\title{
Measurement uncertainties and product classification of water heaters within the framework of the new EU energy labelling and eco-design regulations
}

\author{
Giorgos Panaras ${ }^{1, a}$, Emmanouil Mathioulakis ${ }^{2}$ and Vassilios Belessiotis ${ }^{2}$ \\ ${ }^{1}$ Mechanical Engineers Dpt., University of Western Macedonia, 50100 Kozani, Greece \\ ${ }^{2}$ Solar \& other Energy Systems Laboratory, NCSR "DEMOKRITOS”, 15310 Agia Paraskevi Attikis, Greece
}

\begin{abstract}
Résumé. Le chauffage et l'eau chaude sanitaire représente un élément important de la consommation d'énergie dans le secteur résidentiel. La Commission européenne vise à appliquer des mesures pour réduire la consommation en énergie conventionnelle des dispositifs respectifs, à travers la mise en œuvre prochaine de règlements relatifs à l'étiquetage énergétique et les exigences d'écoconception. Ces règlements sont basés sur la détermination d'un indicateur d'efficacité énergétique convenablement défini, qui tiens compte du rendement du dispositif de production d'énergie conventionnelle utilisé. Dans ce travail, une estimation de l'incertitude relative à la détermination de cet indicateur d'efficacité énergétique est proposée, dans le cas de la production d'eau chaude sanitaire. La discussion porte sur le niveau des incertitudes estimées par rapport aux valeurs-limites proposés par le règlement pour la classification des systèmes ou pour l'examen de conformité avec les exigences imposées par le règlement d'écoconception.
\end{abstract}

\section{INTRODUCTION}

Water heating presents an important element of energy consumption in the residential sector. Several types of systems are commercially available, referring to conventional heaters utilizing a conventional fuel heat source or electrical energy, as well as solar thermal energy systems. The gradual increase of the cost of electrical energy compared with the increase of the cost of conventional fossil fuels, has turned the interest in the application for other technologies as well. One of these refers to the use of heat pumps for water heating purposes [1-3], favored not only by the fast progressing decrease of the equipment cost, but also by the increasing efficiency of the overall process. The most fastly disseminating technology in the residential sector is that of air-water heat-pumps (AWHP), exploiting the ambient enthalpy for water heating. This can be performed through different configurations of the condenser, either immersed in the tank as a wrap-around coil, or externally through a water-to-workingfluid heat exchanger $[3,4]$.

The energy efficiency of systems with equivalent functionality presents a wide range of values which is extended considering the generation efficiency of the energy used. Within this framework, the Commission aims at implementing measures to reduce the conventional energy consumption of the respective devices, through the upcoming implementation of the energy labelling [5] and eco-design regulations [6].

Both schemes use the energy efficiency as reference indicator for water heaters. This indicator aims at providing the necessary information for the efficiency of the system, mainly considering the generation efficiency of the conventional energy used. On the basis of the determined value of the energy efficiency indicator for the specific product, the energy labelling regulation proceeds to a classification of the system, while the eco-design directive imposes specific requirements for the threshold the indicator value has to overcome.

Within this context, it is important for the manufacturer and the consumer to have access to reliable information for the energy efficiency of the system. Even though the measurement and calculating method for determining the energy efficiency values are thoroughly described in the discussed regulations, the presence of measurement uncertainties is inevitable, thus affecting the reliability of the determined value.

The proposed work aims at estimating the uncertainty related with the energy efficiency indicator for water heaters. For the economy of the analysis, a specific type of systems is selected, that of heat pump systems for hot water use, while the generalization of results for the other types of systems is also discussed. The analysis comes through the measurement model and the propagation of the individual

\footnotetext{
${ }^{\mathrm{a} C}$ Corresponding author:gpanaras@uowm.gr
} 
quantities uncertainties, on the basis of the measurement requirements anticipated by the relevant measurement and calculation methods. The discussion investigates the relation of the estimated uncertainties with the limits proposed for the classification of the systems or the requirements set.

\section{MEASUREMENT AND CALCULATION METHODS}

\subsection{Energy Labelling Directive}

The energy labelling directive considers water heaters, including heat pump water heaters, hot water storage tanks and packages of water heater and solar device. The energy efficiency of the systems is determined through the operation for a cycle of 24 hours and implementation of a sequence of draw-offs within a period beginning at 7.00 a.m and ending at 9.45 p.m. Each draw-off is characterized by a specific energy to be extracted from the system, as well as cold water flow rate; specifications regarding the temperature of the hot water are also referred to.

For conventional water heaters and heat pump water heaters, the water heating energy efficiency is calculated as follows:

$$
\eta_{w h}=\frac{Q_{\text {ref }}}{\left(Q_{\text {fuel }}+C C Q_{\text {elec }}\right)(1-S C F \cdot \text { smart })+Q_{\text {cor }}}(1)
$$

Where:

- $Q_{\text {ref }}$ is the useful energy extracted through the sequence of draw-offs, in $\mathrm{kWh}$

- $\quad Q_{\text {elec }}$ is the consumption of electricity over the $24 \mathrm{~h}$ cycle, in $\mathrm{kWh}$

- $\mathrm{CC}$, is a coefficient reflecting the estimated $40 \%$ average EU generation efficiency referred to in Directive 2012/27/EU of the European Parliament and of the Council; the value of the conversion coefficient is $C C=2.5$

- $\quad Q_{\text {fuel }}$ is the consumption of fuels over the $24 \mathrm{~h}$ cycle, in $\mathrm{kWh}$

- SCF (smart control factor), is the water heating energy efficiency gain due to smart control

- Smart, (smart control compliance) denotes the implementation of smart control, i.e. presence of a device that automatically adapts the water heating process to individual usage conditions with the aim of reducing energy consumption

- $\mathrm{Q}_{\text {cor }}$ is a correction factor, taking into account the fact that the place where the water heater is installed is not an isothermal place, expressed in $\mathrm{kWh}$
Actually the discussed relation presents many similarities to the Coefficient Of Performance (COP), as it calculates the useful energy to the consumed one, while taking into account the generation efficiency of electricity (CC factor), as well as the influence of factors as the smart control or the correction with regard to a non-isothermal installation place.

The 24 hour cycle anticipates the set in operation of the system at 12 a.m.; from 12 a.m until 06.59 a.m no draw-off takes place, from 07.00 a.m until 9.45 p.m. a sequence of draw-offs is implemented, while for the time between the last draw-off and 12 a.m. no water draw-off takes place.

The sequence of draw-offs is defined according to the imposed load profile. The directive proposes different load profiles, while the supplier is responsible for the selection of the appropriate one for the specific product.

The rating conditions for heat pump water heaters refer to three different sets of outdoor air conditions, namely average, colder and warmer ones; depending on the heat sink, conditions for the indoor air, exhaust air, brine or water are defined.

Except for the water heating energy efficiency, quantities such as the annual electricity consumption (AEC) or annual fuel consumption (AFC) are calculated accordingly, on the basis of the quantities determined through the testing of the system described just above.

For the case of solar water heaters, the water heating energy efficiency is calculated as follows:

$$
\eta_{w h}=\frac{0.6 \cdot 366 \cdot Q_{r e f}}{Q_{t o t a}}
$$

Where the denominator $\mathrm{Q}_{\text {tota }}$ is calculated according to the following relation:

$$
Q_{\text {tota }}=\frac{Q_{\text {non sol }}}{1.1 \eta_{\text {whon } \text { nol }^{-0.1}}}+Q_{\text {aux }} C C \text { (3) }
$$

Where:

- Qnonsol, is the annual contribution of electricity (expressed in $\mathrm{kWh}$ ) and/or fuels (expressed in $\mathrm{kWh}$ ) to the useful heat output of a solar water heater or a package of water heater and solar device, taking into account the annual amount of heat captured by the solar collector and the heat losses of the solar hot water storage tank; useful energy extracted through the sequence of draw-offs, in $\mathrm{kWh}$

- $\eta_{\text {nh,nonsol }}$ (heat generator water heating energy efficiency), is the water heating energy efficiency of a heat generator which is part of a solar water heater, expressed in \%, established under average climate 
conditions and without using solar heat input; - Qux (auxiliary electricity
consumption), is the annual electricity consumption of a solar water heater or a solar-only system that is due to the pump power consumption and the standby power consumption, expressed in $\mathrm{kWh}$ in terms of final energy;

The energy efficiency classes, proposed in the Directive, are determined according to the water heating energy efficiency $\left(\eta_{\mathrm{wh}}\right)$ and the imposed load profile.

\subsection{Ecodesign Directive}

The Ecodesign Directive addresses manufacturers, indicating specific criteria for water heaters, mainly concerning the energy efficiency of the systems, the storage volume as well as sound power level or emission of nitrogen oxides. For the case of hot storage tanks, the standing losses factor is also calculated; a higher limit is proposed for the value it may present.

Concentrating on the quantity of energy efficiency, the calculation method for the energy efficiency is the same, as in the case of Energy Labelling Directive, noting that for heat pump water heaters measurement in only one set of ambient conditions is performed. The Directive proposes specific limits the energy efficiency should exceed.

\section{ESTIMATION OF UNCERTAINTIES}

For the case of the water heating energy efficiency indicator for conventional water heaters and heat pump water heaters, the estimation of uncertainties should consider the uncertainty of the quantities entering equation (1). Concentrating on a heat pump water heater, where no second conventional source operates, rather than the heat pump, while assuming that no smart function is present and $\mathrm{Q}_{\text {cor }}$ can be considered as negligible, the quantities characterized by uncertainties are the useful energy extracted $\left(\mathrm{Q}_{\mathrm{ref}}\right)$ and the consumption of electricity $\left(\mathrm{Q}_{\text {elec }}\right)$.

Thus, implementing the error propagation law, as described on the Guide to the Expression of Uncertainty in Measurement [7], the following relation can be formulated for the calculation of the energy efficiency standard uncertainty, $\mathrm{u}_{\eta \mathrm{wh}}$ :

$$
\begin{aligned}
& u_{\eta_{w h}}=\sqrt{\frac{\partial^{2} \eta_{w h}}{\partial Q_{\text {ref }}{ }^{2}} u_{Q_{\text {ref }}}^{2}+\frac{\partial^{2} \eta_{w h}}{\partial Q_{\text {elec }}{ }^{2}} u_{Q_{\text {elec }}}^{2}}= \\
& \frac{1}{C C \cdot Q_{\text {elec }}} \sqrt{u_{Q_{\text {ref }}}^{2}+\left(\frac{Q_{\text {ref }}}{Q_{\text {elec }}}\right)^{2} u_{Q_{\text {elec }}}^{2}}
\end{aligned}
$$

The above relation can be further simplified considering that the $\mathrm{Q}_{\text {ref }} / \mathrm{Q}_{\text {elec }}$ ratio is the COP of the heat pump water heater $[8,9]$ :

$$
u_{\eta_{w h}}=\frac{1}{C C \cdot Q_{\text {elec }}} \sqrt{u_{Q_{\text {ref }}}^{2}+C O P^{2} u_{Q_{\text {elec }}}^{2}}
$$

The thermal energy $Q_{\text {ref }}$ is provided by the relation:

$$
Q_{\text {ref }}=\sum_{i=1}^{n} \dot{m} C_{p}\left(T_{\text {out }}-T_{\text {in }}\right) \Delta t
$$

Where:

- $\quad T_{\text {in }}$, is the incoming (cold) water to the system

- $\quad \mathrm{T}_{\text {out }}$, is the outgoing (hot) water to the system

- $\quad \dot{m}$, is the cold (and hot) water flow rate (expressed in $\mathrm{kg} / \mathrm{s}$ )

Actually this relation sums the energy extracted in each draw-off $(i=1$ to $n$ the number of draw-offs anticipated by the testing procedure).

The term $\Delta t$ denotes the duration of each drawoff. Considering the mean value for the flow rate $(\overline{\dot{m}})$ and the temperature difference $\left(\overline{T_{\text {out }}-T_{\text {ln }}}\right)$, and assuming that the uncertainty in the measurement of time can be negligible, the implementation of the propagation of uncertainties law leads to:

$u_{Q_{\text {ref }}}=C_{p} t_{\text {tot }} \sqrt{\left(\overline{\dot{m}} u_{T_{\text {out }}-T_{\text {in }}}\right)^{2}+\left[\left(\overline{T_{\text {out }}-T_{\text {ln }}}\right) u_{\dot{m}}\right]^{2}}$

Noting that:

$$
t_{t o t}=\sum_{i=1}^{n} \Delta t
$$

The term $\mathrm{Q}_{\text {elec }}$ is the sum of the electrical energy consumed by the system through the $24 \mathrm{~h}$ period. Given that the uncertainty in the measurement of time is negligible:

$$
u_{Q_{\text {elec }}}=u_{P_{\text {elec }}}
$$

Where $P_{\text {elec }}$ is the electrical power uncertainty. The uncertainty of the temperature difference can be calculated on the basis of the uncertainties of the individual temperatures:

$$
u_{T_{\text {out }}-T_{\text {in }}}=\sqrt{u_{T_{\text {in }}}^{2}+u_{T_{\text {out }}}^{2}}
$$

Thus, according to the above analysis, the uncertainties of the following quantities enter calculations: $u_{Q_{\text {ref }}}, u_{T_{\text {in }}}, u_{T_{\text {out }}}, u_{\dot{m}}, u_{P_{\text {elec }}}$ Provided that the type A uncertainty component depends on each specific test applied, given the scope of this analysis, it is not included in the discussion; thus, it is the Type B uncertainty component that enters calculations. This component can be considered to refer to the accuracy of the sensors, as anticipated by the Directives (table 1). 
For the direct measurements (flow rate, inletoutlet temperature, electrical power), the assumption of orthogonal distribution leads to:

$$
u_{x}=\frac{\Delta x}{\sqrt{3}}
$$

Where $\Delta x$ is the accuracy of the sensor measuring quantity $\mathrm{x}$ ( $\mathrm{x}$ refers to flow rate, inlet-outlet temperature, electrical power).

The accuracy of each sensor proposed by the Directive is presented in table 1.

\section{RESULTS}

According to relations (5) - (10) and the Type B uncertainties proposed in table 1, the uncertainty of the $\eta_{\text {wh }}$ can be calculated for the load profiles anticipated in the Directive. As it may be seen, the calculated uncertainty also depends on the duration of the draw-offs, as well as on the COP of the heat pump.

According to the relevant literature $[3,10$ 11], the COP of the heat pump can be considered to depend mainly on the exhaust (heat source) and load (heat sink) temperatures; for an air-to-water system these refer to ambient temperature $\left(\mathrm{T}_{\mathrm{a}}\right)$ and the water temperature $\left(\mathrm{T}_{\mathrm{st}}\right)$. The experimental analysis of a relevant system indicated the following relation for the COP [4]:

$$
C O P=4.22-0.072\left(T_{a}-T_{s t}\right)
$$

The ambient temperature is indicated by the Energy Labelling Directive. As noted above, three sets are proposed, the average set indicating dry-bulb temperature of $7{ }^{\circ} \mathrm{C}$, the colder: $2{ }^{\circ} \mathrm{C}$ and the warmer: $14{ }^{\circ} \mathrm{C}$, while the above mentioned average conditions are assumed by the Ecodesign Directive.

Regarding the storage tank temperature of the water heater, this changes through-out the operation of the system, depending also on the set-point temperature of the thermostat. The anticipated draw-offs propose a value for the temperature indicated as $T_{m}$. This temperature is the temperature above which, the water is considered to contribute to the useful energy balance of the user. For a limited number of draw-offs, the proposed value for the temperature $T_{m}$ equals that of the cold water entering the tank $\left(T_{i n}=10{ }^{\circ} \mathrm{C}\right)$; for these cases, the Directive proposes a value for the indicated as the 'peak temperature' $\left(T_{p}\right)$. The 'peak temperature' denotes a minimum water temperature, expressed in degrees Celsius, to be achieved during water draw-off.

Given the above, it can be stated that the storage tank temperature primarily depends on
Table 1. Accuracy of sensors proposed by the Energy Labelling Directive

\begin{tabular}{|c|c|}
\hline Quantity & Accuracy \\
\hline $\begin{array}{c}\text { Hot water (outlet) } \\
\text { temperature }\end{array}$ & $\pm 0.5 \mathrm{~K}$ \\
\hline $\begin{array}{c}\text { Cold water (inlet) } \\
\text { temperature }\end{array}$ & $\pm 0.5 \mathrm{~K}$ \\
\hline Water flow rate & $\pm 2 \%$ \\
\hline Electrical power & $\pm 2 \%$ \\
\hline
\end{tabular}

the operation characteristics of the system, while critical is the set-point temperature, as well as the draw-off conditions. For the needs of the present analysis, calculations have assumed different mean temperatures for the storage tank; a low temperature and a high one have been assumed. The low temperature is consistent with the minimum outlet temperature requirements for the draw-offs. The high one refers to the temperature of the storage tank being equal to the set-point temperature; this set-point temperature should be higher than the indicated 'peak temperature' $\left(T_{p}\right)$.

The uncertainties calculation procedure is described in detail through the implementation in the ' $M$ ' load profile, presented in table 2.

\begin{tabular}{|c|c|c|c|c|}
\hline $\begin{array}{c}\text { time } \\
(h: m: s)\end{array}$ & $\begin{array}{c}\mathbf{Q} \\
(\mathbf{k W h})\end{array}$ & $\begin{array}{c}\mathbf{T}_{\mathrm{m}} \\
\left({ }^{\circ} \mathrm{C}\right)\end{array}$ & $\begin{array}{c}\mathrm{T}_{\mathrm{p}} \\
\left({ }^{\circ} \mathrm{C}\right)\end{array}$ & $\begin{array}{c}\mathbf{f} \\
(\mathrm{l} / \mathrm{min})\end{array}$ \\
\hline $7: 00: 00$ & 0.105 & 25.00 & - & 3 \\
\hline $7: 05: 00$ & 1.400 & 40.00 & - & 6 \\
\hline $7: 30: 00$ & 0.105 & 25.00 & - & 3 \\
\hline $8: 01: 00$ & 0.105 & 25.00 & - & 3 \\
\hline $8: 15: 00$ & 0.105 & 25.00 & - & 3 \\
\hline $8: 30: 00$ & 0.105 & 25.00 & - & 3 \\
\hline $8: 45: 00$ & 0.105 & 25.00 & - & 3 \\
\hline 9:00:00 & 0.105 & 25.00 & - & 3 \\
\hline 9:30:00 & 0.105 & 25.00 & - & 3 \\
\hline $10: 30: 00$ & 0.105 & 10.00 & 40 & 3 \\
\hline $11: 30: 00$ & 0.105 & 25.00 & - & 2 \\
\hline $11: 45: 00$ & 0.105 & 25.00 & - & 2 \\
\hline $12: 45: 00$ & 0.315 & 10.00 & 55 & 4 \\
\hline $14: 30: 00$ & 0.105 & 25.00 & - & 3 \\
\hline $15: 30: 00$ & 0.105 & 25.00 & - & 3 \\
\hline $16: 30: 00$ & 0.105 & 25.00 & - & 3 \\
\hline 18:00:00 & 0.105 & 25.00 & - & 3 \\
\hline $18: 15: 00$ & 0.105 & 40.00 & - & 3 \\
\hline $18: 30: 00$ & 0.105 & 40.00 & - & 3 \\
\hline 19:00:00 & 0.105 & 25.00 & - & 3 \\
\hline $20: 30: 00$ & 0.735 & 10.00 & 55 & 4 \\
\hline
\end{tabular}

Table 2. Operating conditions for load profile $\mathrm{M}$ 


\begin{tabular}{|l|l|l|l|l|}
\hline $21: 15: 00$ & 0.105 & 25.00 & - & 4 \\
\hline $21: 30: 00$ & 1.400 & 40.00 & - & 6 \\
\hline
\end{tabular}

With regard to the requirements set for the specific draw-off profile, and the above discussion, the low mean storage tank temperature is $\mathrm{T}_{\mathrm{st}, \mathrm{M}, \mathrm{l}}=30.01{ }^{\circ} \mathrm{C}$ and $\mathrm{T}_{\mathrm{st}, \mathrm{M}, \mathrm{h}}=55$ ${ }^{\circ} \mathrm{C}$.

Given that the quantity of energy extracted in each draw-off is specific, the duration of draw-offs also depends on the hot water temperature in the water tank. Thus, for $\mathrm{T}_{\mathrm{st}, \mathrm{M} .1}$, $\mathrm{t}_{\mathrm{M}, \mathrm{l}}=61.12 \mathrm{~min}$ and $\mathrm{T}_{\mathrm{st}, \mathrm{M}, \mathrm{h}}=27.19 \mathrm{~min}$.

In table 3 , the results for load profile $\mathrm{M}$ are presented. It should be noted that according to the calculations, for all quantities examined, the relative uncertainty does not depend on the ambient conditions (i.e. the system performance indicator, COP). This can be evident for the thermal energy extracted, including the uncertainty on an absolute basis as well, while the effect of the COP on the electrical energy and the water heating energy efficiency is counterbalanced on a relative quantity level.

Table 3. Load Profile $M$ estimated relative standard uncertainty for useful thermal energy and water heating energy efficiency, determined according to Energy Labelling and Eco-design Directives

\begin{tabular}{|l|c|c|}
\hline $\begin{array}{c}\text { tank temperature } \\
\text { relative uncertainty }\end{array}$ & $\mathrm{T}_{\mathrm{st}, \mathrm{l}}$ & $\mathrm{T}_{\mathrm{st}, \mathrm{h}}$ \\
\hline $\mathrm{u}_{\mathrm{rQ}}(\%)$ & 2.08 & 1.30 \\
$\mathrm{u}_{\mathrm{r}}(\%)$ & 2.38 & 1.74 \\
\hline
\end{tabular}

Following, the relative uncertainties of the water heating efficiency for all load profiles are presented; low and high storage tank temperatures are examined. In table 4, the respective results are presented.

Table 4. Relative standard uncertainties for water heating energy efficiency, determined according to Energy Labelling and Eco-design Directives; all load profiles are examined

\begin{tabular}{|c|c|c|c|c|c|c|c|c|}
\hline $\begin{array}{c}\text { tank } \\
\text { temperature }\end{array}$ & $3 \mathrm{XS}$ & $2 \mathrm{XS}$ & $\mathrm{XS}$ & $\mathrm{S}$ & $\mathrm{M}$ & $\mathrm{L}$ & $\mathrm{XL}$ & $\mathrm{XXL}$ \\
\hline $\mathrm{T}_{\mathrm{st}, \mathrm{l}}$ & 3.17 & 3.17 & 2.31 & 2.47 & 2.38 & 2.90 & 2.84 & 2.86 \\
\hline $\mathrm{T}_{\mathrm{st}, \mathrm{h}}$ & 1.87 & 1.87 & 1.99 & 1.78 & 1.74 & 1.69 & 1.62 & 1.58 \\
\hline
\end{tabular}

It may be seen that the higher mean storage tank temperatures, the higher the relative uncertainty; this can be mainly attributed to the duration of the draw-offs being higher for lower temperatures of hot water, as also discussed above. Moreover, the more energy demanding load profiles, lead in general to lower relative uncertainty values.

Since the testing procedure anticipates the set in operation of the system before the drawoffs, the system would operate and produce hot water before the first draw-off. Thus, the COP of the system by the 24-h period can be different with regard to the calculated one through the draw-off profiles. Nevertheless the relative uncertainty has been proven not to be affected by the value of the COP; within this context, the calculated uncertainties can be considered representative of the complete testing procedure.

\section{CONCLUSIONS}

In this work, the uncertainty related with the water heating efficiency indicator
As it has been discussed, the performance indicator of the heat pump system has been proven not to influence the relative uncertainty value of the complete system water heating efficiency. Within this context, the above results can be considered representative for conventional heaters as well as.

As regards solar water heaters, the uncertainties calculation procedure becomes more complicated, as the calculation procedure requires the testing of the system as solar-only or the exploitation of performance parameters resulting from tests, in order to assess the solar part energy contribution. Nevertheless, since the water heating energy efficiency of the conventional source remains in the equation (2), the discussed uncertainty for the solar system would be greater to some degree.

determination procedure, proposed by Energy Labelling and Eco-design Directives has been estimated. The relative standard uncertainty values present a range between 1.58 and 
$3.17 \%$, depending on the system characteristics and the imposed load profile. On a level of expanded uncertainty, for a confidence level of $95 \%$ and a coverage coefficient equal to 2 , values within a range of 3.16 to $6.34 \%$ are referred to.

Calculations were performed for heat pump hot water systems; nevertheless the analysis demonstrated that the results can be considered representative for conventional heaters, while in the case of solar heaters the uncertainties would be higher, given the contribution of the uncertainty concerning the efficiency of the solar part of the system.

The indicated uncertainty values could potentially affect the classification of the system in Energy classes, given the limits

\section{REFERENCES}

[1] C. Xi, L. Lin, Y. Hongxing, Energ Buildings 43, 1835 (2011)

[2] C.R. Loyd, A.S.D. Kerr, Energ Policy 36, 3807 (2008)

[3] G.L. Morrison, T. Anderson, M. Behnia, Sol Energy 76, 147 (2004)

[4] G. Panaras, E. Mathioulakis, V. Belessiotis, Sol Energy 93, 169 (2013)

[5] EU, Commission Delegated Regulation No 812/2013 supplementing Directive 2010/30/EU of the European Parliament and of the Council with regard to the energy labelling of water heaters, hot water storage tanks and packages of water heater and solar device (2013)

[6] EU, Commission Regulation No 814/2013 implementing Directive 2009/125/EC of the European Parliament and of the Council with regard to ecodesign requirements for water heaters and hot water storage tanks (2013)

[7] BIPM, IEC, IFCC, ILAC, ISO, IUPAC, IUPAP, OIML, Evaluation of Measurement Data - Guide to the Expression of Uncertainty in Measurement (2008)

[8] ISO 5151, Non-ducted air conditioners and heat pumps - Testing and rating for performance (1994)

[9] EN 16147. Heat pumps with electrically driven compressors. Testing and requirements for marking of domestic hot water unit (2011)

[10] C.R. Loyd, A.S.D. Kerr, Energ Policy 36, 3807 (2008)

[11]R.R. Howe, Ms Thesis, Univ. of Wisconsin, Madison (1983) proposed by the Energy Labelling Directive, or characterization of the systems with regard to the lowest performance limits proposed by the Eco-design Directive.

Within this context, both Directives should include a policy for handling the uncertainty in the determined water heating energy efficiency value. The calculation of the failure risk probability for the examined product can contribute towards a reliable and accurate product classification or characterization. Given that the product characterization can be decisive for its release in the market, the market itself should adopt a "fair play" approach, appropriately integrating the practice proposed in the Directive for the uncertainty issue. 